\title{
Bronquiolitis obliterante post-infecciosa: ¿Sudamérica tiene la respuesta?
}

\author{
Post-infectious bronchiolitis obliterans. Does South-America have the answer?
}

La enfermedad pulmonar crónica (EPC) constituye un grupo amplio y heterogéneo de condiciones respiratorias cada vez más frecuentes. El incremento en la sobrevida de muchos pacientes con EPC ha traído consigo la aparición de complicaciones -tanto respiratorias como no respiratoriasque acompañan a niños y adolescentes cada vez más complejos. Los pacientes con EPC exhiben diversos cambios inflamatorios desde el inicio de la injuria (volutrauma, barotrauma, infección) o incluso desde el nacimiento (fibrosis quistica, enfermedad pulmonar intersticial); los cuales persisten hasta el desarrollo, muchas veces inevitable, de cicatrices y/o fibrosis pulmonar. Más aún, diversos patógenos oportunistas, pueden colonizar la vía aérea y participar de la progresión de este daño pulmonar inicial.

La bronquiolitis obliterante $(B O)$ es una condición respiratoria poco frecuente en niños, responsable de la obstrucción y/u obliteración final de la vía aérea pequeña ${ }^{l}$. En países desarrollados, la BO es un síndrome clínico asociado principalmente a trasplantes, mientras que en Asia y Sudamérica $^{3-5}$ a infecciones respiratorias virales. Aunque se reconoce su existencia desde hace muchos años, aún no existe un consenso para establecer su diagnóstico. La BO post-infecciosa es una causa poco frecuente de obstrucción al flujo de aire en niños ${ }^{6}$; sin embargo, por razones epidemiológicas y/o genéticas aun no determinadas, es la forma más frecuente de presentación de este síndrome en Sudamérica ${ }^{7-10}$. Algunos países como Brasil, Argentina y Chile lideran el número de publicaciones

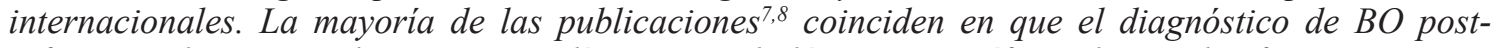
infecciosa descansa sobre aspectos clínicos y radiológicos específicos, los cuales fueron recientemente comentados ${ }^{11}$. Colom y colaboradores ${ }^{9}$ publicaron un puntaje clínico diagnóstico de elevada sensibilidad y especificidad el cual considera a la presencia de adenovirus como el factor de riesgo más importante. Sin lugar a dudas, la tomografía axial computada de alta resolución ha permitido mejorar el entendimiento de muchas condiciones respiratorias ${ }^{12}$. Hoy, gracias a cortes de 1,5 milímetros en la tomografia, la presencia de bronquiectasias, cilíndricas o saculares, centrales o periféricas, generalmente difusas asociadas a un patrón en mosaico de perfusión y disminución de la vascularización, son hallazgos que contribuyen a establecer un diagnóstico certero en la mayoría de las veces. Por lo anterior, el papel de la biopsia pulmonar ha sido cuestionado por su elevada invasividad y poca especificidad. Pese a ello las opciones terapéuticas aún son reducidas y el éxito del cuidado y manejo clínico, dependerá muchas veces de la oportuna intervención antibiótica, una constante kinesioterapia respiratoria y el inicio de una adecuada y precoz rehabilitación pulmonar en la mayoría de los sujetos. Cada vez más se reconoce el papel de la nutrición en el éxito y cuidado de pacientes pediátricos con EPC.

Durante las Jornadas de Otoño del año 2008, la directiva de la Sociedad Chilena de Enfermedades Respiratorias, representada por la Dra. Alexis Strickler, fomentó la creación de una comisión -a través de sus miembros- con el propósito de estudiar este heterogéneo grupo de EPC en niños. La comisión, en coordinación con la Sociedad Chilena de Neumología Pediátrica (SOCHINEP), invitó a un grupo heterogéneo y multidisciplinario de profesionales de la salud constituido por neumólogos, pediatras, enfermeras, kinesiólogos, psicólogos y trabajadora social; considerando oportuno dar inicio a sus actividades con la confección y redacción de una guía clínica en torno a BO post infecciosa. Así, luego de algunos meses de reuniones de trabajo y correos, se diseñó una estructura clínica estandarizada con aspectos en común a muchas EPC, asignando temas de revisión especifica, basado en evidencia publicada, según la afinidad o fortaleza en el tema de cada uno de sus miembros. Prontamente, se logró la participación de destacados profesionales del medio, con quienes además se organizó y dirigió una jornada científica de casi 36 horas en la localidad de Olmué, V Región, en los primeros días de abril del presente año (11). Con el entusiasmo siempre presente, logramos generar un primer borrador, el cual fue enviado a todos los miembros de esta 
comisión, para su discusión, crítica, reflexión y finalmente envío de sugerencias por vía electrónica. Cada autor tuvo acceso a todo el documento en extenso. Luego, en una segunda etapa, la comisión designó un grupo de editores quienes plasmaron las observaciones de cada miembro.

En este número de la Revista Chilena de Enfermedades Respiratorias, presentamos las Guías clínicas para el diagnóstico y cuidado de niños y adolescentes con BO post-infecciosa. Este documento de carácter inédito en Sudamérica, representa la primera herramienta clínica publicada para una aproximación diagnóstica estandarizada en nuestra región. Sin temor a equivocarnos, esta guía clínica representa la primera piedra en nuestro medio que contribuirá al desarrollo del denominado proyecto BOLAT (Bronchiolitis Obliterans in Latin América) diseñado con el propósito de construir una base de datos multinacional para conocer el espectro e impacto de esta condición respiratoria crónica. Consideramos que este documento contribuirá a aumentar nuestro conocimiento en torno a BO post infecciosa, enriqueciendo y optimizando el cuidado de estos menores, y estimando finalmente el grado real de invalidez asociada; pero sobretodo, el grado de recuperación (en términos respiratorios y no respiratorios) de muchos de ellos. Ya que mucha de la información publicada es sobre población adulta (especialmente post-trasplante o asociada a neumonía en organización), es importante resaltar que la elaboración de estas guías está preferentemente situada en el escenario pediátrico. Esperamos sinceramente que estas guías clínicas sean de la utilidad esperada y que el lector disfrute, lo que con esfuerzo hemos elaborado para mejorar la salud de nuestros pequeños pacientes.

\section{Dr. Luis Enrique Vega-Briceño Pediatra Broncopulmonar Presidente, Comisión Nacional Enfermedad Pulmonar Crónica}

\section{Bibliografía}

1.- WOHL M E, CHERNICK V. State of the art: bronchiolitis. Am Rev Resp Dis 1978; 118: 759-81.

2.- KIM C, KIM S, KIM J, KOH Y, COHEN A, DETERDING R R et al. Bronchiolitis obliterans in the 1990s in Korea and the United States. Chest 2001; 120: 1101-06.

3.- FISHER G B, TEPER A M, COLOM A J. Acute viral bronchiolitis and its sequel in developing countries. Paediatrics Respiratory Rev 2002; 3: 298-302.

4.- JONES M H, PITREZ P M, STEIN R T. Post-Infectious Bronchiolitis Obliterans. Pediatr Pulmonol Suppl 2004; 26: 64-5.

5.- PÉREZ M J, KOGAN R, MAGGI L, MENDOZA C. Seguimiento clínico y factores de riesgo en niños con enfermedades respiratorias por adenovirus. Rev Chil Ped 2007; 78: 261-67.

6.- KURLAND G, MICHELSON P. Bronchiolitis obliterans in children. Pediatr Pulmonol 2005; 39: 193-208.

7.- COLOM A J, TEPER A M, VOLLMER W M, DIETTE
G B. Risk factors for the development of bronchiolitis obliterans in children with bronchiolitis. Thorax 2006; 61: 503-6.

8.- CASTRO-RODRÍGUEZ JA, DASZENIES C, GARCÍA M, MEYER R, GONZÁLES R. Adenovirus pneumonia in infants and factors for developing bronchiolitis obliterans: a 5-year follow-up. Pediatr Pulmonol 2006; 41: 947-53.

9.- COLOM A J, TEPER A M. Postinfectious bronchiolitis obliterans. Arch Argent Pediatr 2009; 107: 160-7.

10.- MURTAGH P, GIUBERGIA V, VIALE D, BAUER G, PENA H G. Lower respiratory infections by adenovirus in children. Clinical features and risk factors for bronchiolitis obliterans and mortality. Pediatr Pulmonol 2009; 44: 450-6.

11.- KOPPMANN A. Bronquiolitis obliterante postinfecciosa: Nuevos desafíos para el pediatra neumólogo. Rev Chil Enf Respir 2009; 25: 73-74.

12.- COPLEY S J, PADLEY S P. High-resolution CT of paediatric lung disease. Eur Radiol 2001; 11: 256475. 